\title{
MODEL FOR CRISIS INTERVENTION THROUGH GROUP THERAPY FOR WOMEN WITH BREAST CANCER
}

\author{
Ora Gilbar, PhD
}

\begin{abstract}
This paper describes a model for crisis intervention through group therapy for women with breast cancer. The group sessions, conducted by a multidisciplinary team, are part of the Linn Clinic's post-operative treatment. The discussions using a holistic approach, helped the women to cope more effectively with the disease, the trauma of the operation, and with the chemotherapy or radiation treatment. The women learn that they can do much to regain their health.
\end{abstract}

Many studies have investigated the psychosocial aspects of how women suffering from breast cancer cope with their illness (Asken, 1978; Meyerowitz and Sparks, 1979; Wellisch, 1981). According to Cohen and Lazarus (1979) cancer is an ongoing event of stress that begins with the appearance of the first symptoms and continues with the physiological tests leading to diagnosis, the surgery, the chemotherapy or radiation treatments, and the medical follow-up. At each stage the patient senses a threat to life, to wholeness of body, to self-perception, to mental balance, and social functioning.

Clinical and experimental experience has shown that the most difficult stage facing the cancer patient after breast surgery is that of the chemotherapy and/or radiation therapy (Meyerowitz and Spark, 1979). Several studies have also indicated a connection between mental state and time of survival in breast cancer patients (Hislop, Waxler et al., 1987, Levey, Lee et. al., 1988). For this reason the social workers at the Oncological Institute at the Linn Clinic in Haifa, Israel decided to form groups of post-mastectomy patients when they came to the institute for continuation of medical treatment. These groups were first formed in 
CLINICAL SOCIAL WORK JOURNAL

1982, ${ }^{1}$ since then 18 groups have functioned. In the course of the work with them the team of social workers designed a therapy model, which is described in detail in this article.

\section{Crisis Intervention through Group Therapy}

In a situation of "Intervention through group therapy" a group of unacquainted and unrelated individuals meet with the therapist in order to gain an understanding of the stress situation of each. The aim of the treatment is to make the group members more aware of the difficulties with which they must cope. The treatment focuses on the day-today problems that worry the group members and about which they seek help.

The individuals in the group discuss their ability to manage their situation and support systems. Together they examine what is currently taking place and what prevents them from functioning as they would like. The members soon become actively involved in offering each other assistance and support. By guiding the conversation, the social worker actively and directly assist the participants in the discussion to focus on the problem. The social worker must sense the nonverbal messages of the group members, be receptive to them, and provide affirmation of the feelings they express (Aguilera and Messick, 1982).

The subjects selected for discussion at the meetings are based largely on the holistic approach to cancer treatment. The special feature of this approach is the ability of the patient to oversee his life and his illness; the patient is thus an active partner in the treatment (Simonton et al., 1978; Seigel, 1986). The underlying concept is of a link between the body and the mind. In other words, failure to copy properly with stress may cause a weakening of the immune system and thereby lead to the onset of illness. The aim of the medical treatment is to reduce the cancer (or to prevent its recurrence) by increasing immune activity or by lowering the number of affected cells. This may come about through surgery, radiation, or chemotherapy. As immunological treatment is still at its initial stage, the aim of the holistic approach is to influence the immune system by directing the mental state towards health. According to this theory, after understanding the psychological reasons that may have contributed to the onset of the illness, the patient can learn to overcome the resentment and anger that the illness or connected events have caused. The patient learns to make use of relaxation and guided imagination, which are effective means of encouraging a be-

${ }^{1}$ The preliminary results of the work with these groups were processed in 1982-83. See Gilbar, O., \& Mozer, R., Social Group Work for Women after Mastectomy: Rehabilitation Attitude, Hevra ve Revaha, Vol. 2, 1983, (Hebrew). 
ORA GILBAR

lief in the ability to become well. Correct diet, the importance of physical exercise, coping with the fear of a recurrence of the illness, and setting goals for periods of three months, six months, and a year are all taught. The setting of goals constitutes a declaration that there are things the patient wishes to do and reflects the feeling that they will indeed be achieved. Finally, the importance of the participation of the family in the process is emphasized.

In our model the importance of participation by the family in the fight against the disease is emphasized, while locating the stress factors in the outbreak of the disease plays a smaller part.

\section{Preparation for Group Work}

A monthly average of 18 women patients with breast cancer who have undergone surgical intervention (complete mastectomy or lymphectomy) are referred to the institute. Almost all the women were operated upon in the same hospital. Every woman who underwent surgery is invited to become a member of a group during the year following the operation. The meetings take place at the Oncological Institute once a week, and last for an hour and a half. The first 30 minutes are devoted to physiotherapy exercises. The last 55 minutes involve a discussion with the group leaders. There is a coffee break between the two parts of the meeting. The aim of the physiotherapy exercises is to show the importance of bodily activity in the rehabilitation process in general and to strengthen the arm on the side of the operated breast in particular. This is to prevent disability in moving the arm.

\section{The Course of the Meetings}

The course of each of the eight meetings is described below. The main subjects discussed at each meeting are presented first, followed by a description of the atmosphere in the group, and finally by an evaluation of the program of the meeting. The purpose of the description that follows is to present the model; it does not consider the individual characteristics of each group.

\section{FIRST MEETING}

\section{Subject: Making Acquaintance}

The atmosphere at the first meeting is formal despite the fact that sometimes several women know each other from the period of hospitalization. The women in the group do not know what to expect from the meetings, even though the purpose was explained to each in individual 
conversations. The physiotherapy exercises together with explanations at the start of the meeting help to dispel the tension.

At the first meeting the therapist outlines the goals as well as the dates and lengths of the meetings. She emphasizes the importance of being present at every meeting. Next, each of the participants is asked to introduce herself. Most choose to begin with a frank account of the discovery of the tumor. They then describe the operation and the time in hospital. Although the descriptions are detailed they are very rarely accompanied by expressions of emotion. The need of the participants to involve the group members in each particular of the illness often leads to impatience among the listeners so that they begin to chat among themselves. At the same time, none of them foregoes the presentation of a full and detailed report. The therapist allows each woman to express herself, thereby promoting an atmosphere of acceptance and support. There are usually one or two who bring up the matter of their hesitation about joining the group, as they are healthy and are functioning as they did before.

At the close of the meeting the therapist stresses that the goal of the group is the acquisition of important coping skills, the members learning from each other's experience.

\section{SECOND MEETING}

\section{Subject: The First Emotional Reaction to the Operation}

The atmosphere at this meeting is still formal, although the beginnings of a certain closeness among the participants is felt. The women are asked to focus on their feelings following the operation. In describing this, there are frequently sharp outbursts of anger. The most frequent reasons given for these concern the impersonal attitude of the medical team at the hospital. This team often ignored what the patient had to say about the operation, even though the subject matter was that of the woman's own body. In other cases it was the disregard shown by the family doctor to the complaint of a lump in the breast. As the meeting proceeds the therapist raises the possibility that the source of the anger lies elsewhere-outrage that it was their fate to become cancer sufferers.

Some of the participants asked: "But why me?" expressing their anger at God. Two women, who were Holocaust survivors, asked why they had been forced to suffer two traumatic events in one lifetime. One of them put it this way: "I experienced all the torments of hell in the concentration camps and I lost all the members of my family. I finally made it to Israel, and even though life was at first difficult here, I man- 
aged somehow to establish a family and to have children of my own. Now that I have the opportunity to forget some of my past suffering and to begin to enjoy life, along comes this horrible disease that has been sent for me special delivery. And this is the legacy that I shall be giving to my daughter." The anger expressed here was accompanied by a feeling of utter helplessness: "There is simply nothing I can do about the situation, except to wait and see whether I have been chosen to remain among the living or not."

The women nod their heads, signifying their identification and agreement with what they have heard. The therapist gives legitimation to the feelings of anger, and adds that the sense of helplessness accompanying cancer is frequently no less difficult than the treatment itself. The feeling could often be reduced by active participation in the treatment process, for example, by a correct diet, physical activity, positive thinking, learning relaxation and guided imagination, and setting new life targets. The co-therapist adds that the coping which the participant has described shows that she is able to deal with difficult situations.

Towards the end of the meeting there is a feeling of alleviation as a result of the legitimation given by the therapist to the expression of anger.

\section{THIRD MEETING}

\section{Subject: Medical Information}

As early as the first and second meetings the women raise medical questions regarding cancer and the ways of treating it. Similarly it becomes apparent that some of the medical information the women possess is incorrect and this adds to their fears. Therefore, a doctor is invited to this meeting. The atmosphere at first is relaxed but the entrance of the doctor creates tension. The group members usually present many and varied questions, such as: Is cancer contagious? Is it hereditary? What disabilities arise as a result of the operation? The doctor's replies are clear and detailed, with emphasis on the positive aspects of the medical treatment in dealing with the illness. The doctor also notes the importance of physiotherapy and learning additional coping skills as contributory elements in the curative process. During this meeting the doctor is also asked about correct diet. Towards the end of the meeting the tension decreases and there is a sense of ease owing to the acquisition of reliable medical information and to the awareness among the patients that all their medical problems will be answered. 
CLINICAL SOCIAL WORK JOURNAL

\section{FOURTH AND FIFTH MEETINGS}

\section{Subject: The Emotional Responses to the Significance of the Diagnosis}

The atmosphere at this meeting is informal and some intimacy is already noticeable among the participants. The women are asked to take a slip of paper from an open pile of slips, on each of which the name of a particular emotion is written. The choices are: depression, guilt, anger, shock, shame, worthlessness, fear. A blank slip may be chosen. Each woman is asked to describe her feelings relative to the word on the slip she has selected. Often in the course of the account there are outbursts of weeping and rage, expressing immense pain.

A large number of group members choose the slip marked "depression." One of them observes that her feelings of depression arise from her being unlike what she was prior to the operation and her fear that she will never again be as she was. The therapist states that the diagnosis of breast cancer causes a change in the patient and in the family. Sometimes it is seen that the change caused by this difficult experience has elicited positive manifestations, such as support by the family, in whom feelings of closeness are aroused; or a decision may be made to do things that previously were not done. The women who have chosen the blank slip also describe their feelings. Most explain this choice by stating that all is well with them, and that is also how they felt immediately after the operation.

In the next part of the meeting the participants are asked to choose a slip on which a word is written expressing a feeling appropriate for their partner or children. This request is met by many women with surprise and even a hint of anger: Why should the situation be difficult for the partners? They are not the ones who are ill. However, as the meeting progresses the participants come to understand that cancer is not their "private" illness and that it arouses fear, alarm, anger and worry in each member of the family. The leader encourages the participants to talk about the family's feelings with members of the family. In this way, the patients feel easier-a sense of warmth and intimacy, which is important in the process of coping with the illness.

At the end of the fifth meeting the therapist outlines existing knowledge on the emotional responses of the woman and the family on receiving the diagnosis. The therapist presents the theoretical model of Kubler-Ross (Kubler-Ross, 1976) on the stages of reaction to death: denial, anger, bargaining, depression, and acceptance. Most of the women express surprise at the extent to which the theoretical model conforms to what they themselves are experiencing. They ask if these processes may be made easier. The therapist describes the possible use of the tech- 
nique of relaxation and guided imagination and invites those interested in it to make an personal appointment with her.

\section{SIXTH MEETING}

\section{Subject: Setting Goals}

The atmosphere at this meeting is one of proximity and cohesion. The therapist describes the great advantage of establishing new goals in coping with the illness. It turns out that for most of the women this is the first time that they have consciously spelt out their reasons for living. This is a kind of declaration that there are things that the woman desires from life, and will therefore make every effort to achieve them. It is a way of turning emotional, spiritual and physical needs into a behavior that affirms life and of renewing it energetically. Usually several women express opposition to setting goals, possibly because they doubt their ability to achieve them and fear failure. It may also be because they feel that there is no point in setting goals as they do not believe that they will live long enough to realize them. The therapist notes that the setting of long-and short-term goals is important as it helps to bring the reasons for living into focus and re-establishes the link with life. In cases where it is difficult for the participants to find life goals, the therapist, the co-therapist and other group members help in making the choice.

\section{SEVENTH MEETING}

Subject: Self-perception of the Woman after Mastectomy

A beautician is invited to this meeting. Her arrival elicits a relaxed atmosphere. She talks with the women about the beneficial effect of external appearance on mood, and teaches them simple techniques (with some of the women acting as models) by which they can improve their external appearance. The aim of the meeting with the beautician is to encourage each woman to talk about her feelings regarding the change in appearance of their body and how this affects her intimate relations with her partner through a non-threatening stimulus, as most people find it difficult to talk about this relationship, especially in a group. In most cases the discussion develops along these lines, though not without embarrassment and hesitation. It turns out that some of the women have not yet dared to undress in the presence of their spouse. In addition, they themselves are not prepared to look at the scar, as they fear 
rejection, repugnance and non-femininity. At this juncture, the therapist emphasizes personality as the principal variable in the attraction of the spouse. In the course of the meeting the therapist devotes some time to the information that exists on the subject of change in self-perception in women after surgery. Finally she presents the possibility of breast reconstruction.

\section{EIGHTH MEETING}

\section{Subject: Summing Up and Dispersing}

The atmosphere at this meeting is one of sadness mixed with satisfaction. Several of the women always check the possibility of continuing the meetings or at least of joining the next group to form. The therapist asks each of the women to recount her feelings in the course of the meetings. All observe that the discussions in the group framework have afforded them great comfort by virtue of the medical and emotional information and by virtue of the feeling of community of fate: "I am not alone in finding it hard to cope with the illness." Other women feel the same way: therefore "I am normal." Similarly the participants note the great benefit in involving each other in the day-to-day problems and in finding solutions for them: for example, how to manage with a nightdress without the prosthesis; or diet when undergoing chemotherapy. As the meeting proceeds the women state how difficult it is for them to leave. Usually they exchange addresses and make plans to meet at each others' homes.

Finally, the therapist sums up the meetings and emphasizes that the therapy team is available for any question or problem that may arise in the future.

\section{The Unique Impact of the Group Sessions}

The group sessions provided an outlet for previously pent-up emotions as well as a context for the promotion of mutual support. The discovery that she is not alone in her suffering and her struggle can significantly alleviate the physical and emotional pain of the breast cancer patient. Even the opportunity to cry and to know that those around her understand the reasons for her tears is of vital importance and helps diminish the feeling of isolation; as one of the participants put it: "I am not alone; I have partners." "Approval" for the release of these emotions came from both the participants and the social worker. Although there was a feeling of shared fate, the participants never lost the sense of the uniqueness of their struggle. This was expressed in the interaction between the participants. They provided mutual support and offered each 
other concrete solutions for the various problems of day-to-day living, such as how to cope when suffering from fear of death or what to eat or cook when one has an attack of nausea. The participants even tried jointly to solve deeper emotional problems, such as breaking up a relationship with a husband. Whenever a participant was unable to cope with the particular topic of the group discussion, she would turn to another participant for a brief tete-a-tete.

Perhaps the unique impact of these interventions can be best illustrated by the case history of one participant. Mrs. A. was married and had five children, three of them married, one single daughter aged 21 and one son aged 14 . She had undergone mastectomy, following which the social worker in her interviews found Mrs. A. to be generally content. Immediately after surgery she resumed her daily routine. Although she already had a part-time job, Mrs. A. was looking for more work. As before her operation, she continued to look after the house, to invite her married children for dinner, and to attend to her appearance. On the surface, at least, the mastectomy had not seriously disrupted her life. However, soon afterwards she began to suffer pains in various parts of her body. Thorough medical examination revealed no physiological cause for the pain, and the physician referred Mrs. A. to the social worker. The remedy, as far as Mrs. A. was concerned, was simple "If the doctor would only give me something for the pain, everything would be just fine."

The social worker presented Mrs. A. with the idea that there was a link between the body and the mind. In other words the physical pain might have been a symptom of fear or dread. She suggested to Mrs. A. that they meet several times to talk about the operation and the illness.

When the group meetings began, Mrs. A. agreed to be a participant. At the first sessions she burst into tears as the discussion began to revolve around the subject of death. She left the group in order to cry in an adjacent room. The co-therapist went out to talk with her. In tears, Mrs. A. turned to her, saying: "What is happening to me? I have never cried before in my life, not even in hospital after the surgery. Anyway, everything is OK now. As you can see. I have stopped crying." And she immediately burst into tears once more. She wanted to go home but said that she would come back for the next session. However, she wondered out loud how she would be able to go out into the street, since everybody would be sure to see that she had been crying. The social worker told her that usually the diagnosis of cancer caused feelings of distress and weeping. She advised her to rejoin the group. Mrs. A. took the advice and in a few minutes joined the discussion again. The other participants welcomed her back with soothing expressions of acceptance and warmth. Mrs. A. sat down and listened to the others without making any comments. After the group meeting ended the co-therapist spoke to 
Mrs. A. in private. Mrs. A. began to cry again, repeating the statement that she had never cried before and wondering why she had become so emotional on that particular occasion.

This event proved to be a turning point in Mrs. A.'s treatment process. In the ensuing interviews with the co-therapist, it became apparent that the group sessions had brought to the surface all the subjects Mrs. A. had been trying to deny. The discovery that she was not the only one to fear death gave her the courage and the strength to verbalize her feelings, uncertainties, fears and innermost thoughts. After a few weeks, the pains disappeared.

\section{The Therapist: Transference and Countertransference}

Yalom (1975) stated that the therapist cannot focus attention purely upon transference and at the same time hope to utilize the large number of other potential curative factors. One of the processes occurring that cannot be utilized in the breast cancer intervention group is transference. Yet this does not mean that such processes do not exist, as may be illustrated by the following case. Mrs. M. decided to stop receiving chemotherapy. She did not mention this in the course of the meeting but only at the end, and then as a statement, not as a subject for discussion by the group. She did not attend the next group meeting. One of the participants expressed great anger at the group therapists for not fulfilling their tasks; in her view, it was their job to see to it that Mrs. M. did not give up chemotherapy. Three other group members adopted this position also. In the discussion that developed two of the women spoke of their disappointment with the group therapists, charging that their behavior expressed lack of concern. The therapist pointed out that it was indeed her task to attend to each of the women but only in a limited way, because they were responsible for their lives. The co-therapist noted that she did not really regard it as her duty to deal with the question of accepting medical treatment. The participant who raised the subject became very angry with the co-therapist, insisting that it was the duty of the therapist to take care of the patients. As the discussion continued this woman said that if her mother had been alive, she would not have suffered from cancer. An attempt by the therapist to discuss this met with opposition. This example is one of transference of the participant. It may be surmised that the woman transferred her feelings towards her mother to the therapist, and reacted to her accordingly. That is, she saw in the therapist a mother figure who cared for her, and so she would be protected. The therapist indeed felt that her task was to care for and protect the woman. Moreover, the therapist felt that she had to compensate the woman for the loss of her breast. This, she believed, was the least she could do in a situation where the loss was so 
ORA GILBAR

threatening. With the co-therapist the countertransference processes were different. It seemed that not only did she not take responsibility for the refusal of the patient to accept medical treatment, she reacted angrily to the fact that the woman expected her to fulfil a role that she could not, or would not undertake.

\section{CONCLUSIONS}

Intervention through breast cancer has become an inseparable part of the treatment that every cancer patient undergoes following breast surgery. A total of 160 women have taken part in the therapy groups. The above experiment demonstrated to the multidisciplinary team at the Linn Clinic's Oncological Institute the importance of this kind of intervention for post-mastectomy patients. The discussions through the holistic approach helped the women to cope more effectively with the disease, the trauma of the operation, the chemotherapy or radiation treatment. The women were now better able to adjust to their new situation and to resume their previous level of functioning, and have the feeling that they can do much to be healthy.

The impact of the group discussions was surprisingly long-term and extensive. The participants continued to show interest in and concern for each other even after the series of meetings was over, as could be seen through their conversations in the institute's corridor while awaiting the treatment sessions. These conversations in turn made other patients aware of the group context and induced some of them to inquire about joining.

The raised spirits of the participants immensely improved the institute's image and atmosphere. It was no longer seen merely as a grim place where the cancer patient received treatments which while helping her to recover also caused considerable discomfort. It was now also seen as a place where she could receive help that could promote immediate improvement and could ease her emotional burden.

Comments from the participants reflected this transformation: "This is a place where we can say things that could not be said anywhere else, and that is worth a million." "It gave me a wonderful feeling to be asked to take part in a program that really brings relief. Nobody has ever given me help before without my first asking for it." "The exercises here really help and they also remind me to do some exercises at home."

Today, participation in the group sessions is an integral part of the treatment process for all of the institute's patients who have undergone mastectomy, lymphectomy and bilateral mastectomy.

Finally, the aim of the team is to establish a group with the partici- 
CLINICAL SOCIAL WORK JOURNAL,

pation of each patient's spouse. This is because of the importance of family support in the process of recovery from the illness.

\section{REFERENCES}

Aguilera, D.C. and Messick, J. (1982). Crisis intervention. London: Mosby Company.

Asken, M.J. (1975). Psychoemotional aspects of mastectomy: A review of recent literature. The American Journal of Psychiatry, Jan., 143, pp. 56-59.

Cohen, F. and Lazarus, N.S. (1979). Coping with stresses of illness in Stone, G.C., Cohen, F., et al. Health psychology-A handbook. Jossey Bass Publishers, San Francisco, pp. 217-254.

Levey, S.M., Lee, J., Bagley C., et al., Survival hazards analysis in first recurrent breast cancer patients: seven year follow-up.

Hislop, T.G., Waxler N.E., Coldman, A.J., et al., The prognostic significance of psychosocial factors in women with breast cancer. Journal of Chronic Disease, 40, 1987, pp. 729-735.

Kubler-Ross, E. (1976). On death and dying. London, Tavistock.

Meyerowitz, B.E., Spark, F. et al. (1979). Adjuvent chemotherapy for breast carcinoma, Psychosocial implication, Cancer, May, 84, pp. 1613-1618.

Seigel, R. (1986). Love medicine and miracles, Rider \& Co., Publisher.

Simonton, O.C., Simonton, S.M., and Creighton, J.L. (1987). Getting well again, Bantam Books, N.Y.

Wellisch, D.K. (1981). Family relationships of the mastectomy patient: Interactions with spouse and children, Israel Journal of Science, pp. 993-996.

Yalom, E.D. (1976). The theory and practice of group psychotherapy, Second Edition, Basic Books Inc. Publishers, N.Y.

Ora Gilbar, $P h D$

University of Haifa

School of Social Work

Haifa 31999, Israel 